\title{
对少数民族汉语教师职后培训的思考
}

\author{
沙力玛・木拉提
}

新疆博尔塔拉职业技术学院

DOI:10.32629/er.v3i1.2389

[摘 要] 国语教育就是民族教育的基础,其对民族教育,地方经济发展,维护社会和祖国统一具有十分重要的意义。作为一名人民教师,如果不懂 国语就不能很好地了解和理解政策,不能培养好我们未来接班人,工作能力的发挥就会受到限制,就不能为孩子们很好的服务。在民族地区学校 中, 有很多少数民族汉语教师, 因多种因素导致其普通话水平较低, 专业能力相对薄弱。因此, 只有通过参加专业培训才能达到一个合格的汉语教 师的标准。本文针对目前存在的汉语教师教学水平差, 进修机会少等几个方面分析问题所在, 试着从校企合作、设置普通话等级标准、团队结构 改革和综合素质提升等几个方面谈谈少数民族汉语教师职后培训的一些思考。

[关键词] 少数民族; 汉语教师; 职后培训

我国是一个多民族的大家庭, 社会稳定和祖国统一是各民族人民的共 同愿望。语言是一种交流的工具, 又是一个沟通的桥梁。汉语作为国家通 用语言文字, 是各民族文化交流交融的桥梁, 对于地方经济发展, 维护社会 稳定和祖国统一具有十分重要的意义。在培养各民族学生学习科学文化知 识, 让其成为国家需要的 “民汉兼通” 人才的教育事业中, 汉语教师的功不 可没。但要充分发挥汉语教师的作用, 还需提高汉语教师的综合素质, 特别 是对少数民族地区的汉语教师而言, 其职后培训工作十分重要, 因此, 对少 数民族汉语教师的培训加以研究是很有必要的。

\section{1 当前少数民族汉语教师中存在的问题}

结合本人几年的汉语课教学经验, 以及在职后参加国家汉语骨干教师 培训时的一些经验交流后, 发现很多少数民族教师中存在有很多共性的问 题。一下我从几个方面作以分析:

\section{1 汉语教师教学水平有待提升}

在很多民族地区实行双语教育已有很多年, 这要求学生在高中毕业 时能达到 “民汉兼通” 的标准。民族地区的各项建设事业需要教育能培 养出高素质的劳动者和科技创新人才, 特别是培养德才兼备、民汉兼通 的高素质的少数民族劳动者和科技创新人才。目前, 几乎所有地区都从 小学开始设有汉语课程, 但实际上学生的汉语 “听、说、读、写” 能力 并不强。汉语作为基础课, 是学好其他科学文化课程的前提, 若语言关不 过关就很容易影响其他课程的学习。学生汉语水平的高低, 有诸多因素 导致的, 但其中教师的教学水平也成为重要因素。在汉语课教师队伍中,

通过对单摆的分析, 不难看出, 摆球是经过轻绳的拉动围绕一定点进 行的往复运动, 由此, 单摆这一运动模型应该被简化为转动。在最低点时, 我们找准单摆的运动定位后, 将其准确地定义为转动, 如图 1 , 摆球此时的 角加速度为 0 , 处于瞬间的平衡, 故而在这一位置的摆球就是平衡的状态, 此时我们才能将单摆的最低点称为 “平衡位置”。

但目前市面上主流的高中物理教科书存在的问题笔者认为是可以解 决的。倘若在目前主流教科书针对单摆这一知识点的讲解基础上将单摆归 类为转动, 再增添角加速度的知识点, 运用如图 1 的分析, 这一问题就可迎 刃而解, 学生也就再也不会纠结于 “单摆的最低点分明受力不平衡, 为何被 定义为 '平衡位置” ? ”这一问题。但从学生接受程度和学习任务考量, 这样的话目前的物理教材就需要增添许多基础知识。

\section{[参考文献]}

[1]段文玉.对单摆平衡位置的“质疑” [J].中学物理教学参考,2002(4):21. [2]朱琴.对单摆平衡位置的“释疑” [J].中学物理教学参考,2002(10):35.
有相当多的少数民族教师, 其中部分汉语教师自身汉语水平有限, 缺乏 语言理论知识, 不懂语法, 词汇量不足, 发音不准, 乃至发音错误的情况 普遍存在, 在汉字书写顺序方面也问题较多, 可以说其专业水平参差不齐, 且越到基层, 这种问题越严重, 这也对少数民族汉语教学质量的提升造成 了严重的影响。

\section{2 汉语教师资源短缺}

双语教学实行多年以来, 双语教师严重短缺, 不仅影响着教学质量 的提高, 而且制约着双语教学规模的进一步发展。从整体看, 现有双语教 师的汉语水平达不到推进双语教学的基本要求, 严重制约了双语教学的 进一步发展。针对少数民族地区汉语教师数量短缺, 教师教学质量不高 的情况, 教育部门也采取了诸多措施, 但问题仍然存在。随着双语教学班 数和学生人数的不断扩大, 一名汉语教师往往需要负责多个班的汉语教 学任务, 也有教师同时承担母语授课的教学任务, 这导致汉语教师工作 任务繁重, 使得师资短缺的矛盾更加加重。因此也有很多教师疲于应付 上课, 难以分出时间和精力对课程教学进行研究, 使得汉语教学水平难 以得到有效的提升。

\section{3语教师队伍汉中存在较多的少数民族成员}

相关部门针对少数民族区域的汉语教师进行了详细的调查和分析, 发 现很多学校当中的汉语教师都是由少数民族人员担任, 特别是在小学当中, 几乎所有汉语教师都是少数民族人员, 这些教师为少数民族的汉语教学做 出了巨大的贡献, 但这些教师自身的专业水平却也是不容忽视的。很多教

[3]黄志坚.也谈单摆的 “平衡位置” [J].物理教学探讨,2003(3):47-48.

[4]教育科学出版社.普通高中课程标准实验教科书物理选修 3-4[M]. 四川: 四川教育出版社重印,2011:2.

[5]人民教育出版社,课程教材研究所,物理课程教材研究开发中心.普 通高中课程标准实验教科书物理选修3-4[M]. 第三版, 北京: 人民教育出版 社,2010:2.

[6] 上海科技教育出版社.普通高中课程标准实验教科书物理选修 $3-4[M]$.上海: 上海科技教育出版社,2007:3.

[7]江苏教育出版社.普通高中课程标准实验教科书物理选修 2-2[M]. 江苏:江苏教育出版社,2007:1-8.

作者简介:

李兴春(1995--), 女, 汉族, 四川省绵阳市梓潼县人, 研究生在读, 现 就读于西华师范大学物理与空间科学学院课程与教学论专业, 研究方 向: 高中物理教学理论及实践策略 
师并不是汉语专业毕业的, 有体育专业的、思政专业的、历史专业的等 等, 只是能够运用汉语进行正常的交流而已, 并未接受过系统的汉语教 学培训, 也不了解怎样进行汉语技能培训, 这也对汉语教学的质量造成 了不利影响。

1. 4 汉语教师进修提升机会有限

据了解, 在进入少数民族学校进行汉语教学以后, 教师几乎没有机会 再进行深造, 其教学理念以及教学方法一直无法得到有效革新, 即便学校 会安排一些培训工作, 但也大多是以评职称为目的的, 仅仅是利用假期去 往指定学校学习一个月, 然后拿到继续教育证即可, 或者是在使用新教材 以后, 针对新教材进行 1-2周的培训, 这也导致大部分教师在汉语教学方面 存在教学理念及方法陈旧的问题, 甚至只是停留在简单的翻译上, 无法保 证学生的汉语学习质量。

\section{2 加强少数民族汉语教师培训的具体措施}

2.1 与高校加强合作

就目前的少数民族汉语教育情况来看, 汉语教育已经得到了有效的普 及, 不仅义务教育阶段会进行汉语教学, 幼儿园教育也已经开始实施双语 教学, 但就目前的汉语教师培养情况来看, 还存在高校人才无法适应社会 发展趋势的情况, 对此, 地方政府部门应该与高校加强合作, 有针对性的开 展教师培养工作, 确保教师的专业水平能够适应汉语教育的相关需求, 并 缓解基层专业汉语教师短缺的情况, 使少数民族区域的汉语教育能够得到 快速的发展。

2. 2 针对少数民族汉语教师应该设置普通话等级标准

目前, 根据国家相关规定, 所有师范类高校学生在毕业以前都需要参 加普通话考试, 在普通话达到相应标准以后才可以拿到毕业证和考取教师 资格证, 如此才能进入教学岗位, 但在部分少数民族区域, 由于汉语教师资 源紧缺, 学校并没有对教师的普通话标准进行严格的审核, 从而导致教师 汉语水平不高的情况, 对此, 少数民族地区的相关部门及学校必须要加强 监管, 要针对少数民族汉语教师设置普通话准入制度, 要根据应聘教师的 普通话水平判断是是否适合汉语教师岗位。

2. 3对教师团队的结构进行改变

对于少数民族学生而言, 其在汉语言方面的语音面貌会对整体语言面 貌造成巨大的影响, 而语言的基础应该从小打好, 因此, 汉语教学应该从娃 娃抓起。而我们知道语言面貌的改变是很难的, 若少数民族学生在小学阶 段的汉语学习中, 未能得到良好的发音训练, 那么在进入大学以后, 想要将 其语言面貌改变几乎是不可能的, 而目前汉语语言面貌恰恰是影响少数民 族学生汉语水平的主要原因, 因此, 为了提升汉语教学的质量, 需要从小学 阶段开始, 设置合格的专业教师进行授课, 使少数民族学生的汉语语言面
貌得到有效的改善。

2. 4对教师团队的综合素质进行全面的提升

针对汉语教师综合素质参差不齐的情况, 地方政府及学校应该进行积 极的改善, 一方面要对高素质的汉语教师进行积极的引入, 通过引入高素 质的人才, 引进先进的教学理念及教学方法, 并通过教师之间的沟通、交流 以及学习, 提升汉语教师队伍的整体水平, 而且这样也能确保汉语教师的 足额配备, 避免教师工作量过大, 而影响教研活动, 使汉语教师能够有更多 的空间和时间去自我提升, 改善教学方法, 提升教学质量。另一方面, 学校 应该针对现有汉语教师加强培训教育工作, 要通过定期的培训, 专业的指 导, 学术交流等方式, 对现有汉语教师的专业水平进行不断的提升, 特别是 非汉语专业出身的教师, 应该支持、鼓励教师进行普通话标准的考试, 并为 这些教师提供学习深造的机会, 使其能够更好的适应少数民族汉语教学的 相关需求, 从而有效提升汉语教学的质量。

2.5 对培训教材进行编写

从某种程度上来讲, 汉语教师的培养是一项系统性的工作, 在其培养 过程中, 需要有科学的培养体系作为支撑, 特别是培训教材, 必须要具备专 业性与可行性。要避免那种为了评职称走走过场的形式化培训, 在教师培 训方面, 首先就是要保证培训的时间, 最起码培训时间要在半年左右, 而在 教材方面, 要由专业部门和人员进行编制, 并由权威部门审核通过以后才 能正式用于教师的培训, 使其能够对现代教育中前沿的内容进行反映, 通 过这种方式将汉语教师培训方面的问题有效解决, 以此来提升教师职后培 训的质量, 改善汉语教学质量不高的问题。

\section{3 结语}

综上所述, 加强对少数民族汉语教师的职后培训, 能够使汉语教师的 专业水平得到全面有效的提升, 这对于少数民族汉语教学质量的提升具有 非常重要的意义, 因此, 相关政府部门、各大高校以及少数民族学校一定要 对汉语教师的培训保持高度的重视, 要通过科学的培训、严格的考核, 确保 汉语教师的专业能力, 使其能够在汉语教学岗位上充分发挥作用, 有效提 升少数民族学生的汉语水平。

\section{[参考文献]}

[1]刘爱华.对少数民族汉语教师“培训”之我见[J].新教育时代电子 杂志(教师版),2018,13(25):256。

[2]米花兰.对少数民族汉语教师 “培养” 和 “培训”之我见[J].喀什 师范学院学报,2016,34(1):102-105.

[3]代猛.对新疆少数民族教师汉语言培训工作的几点建议[J].读写算 (教育教学研究),2016,21(40):128-129. 